\title{
Ocean warming compresses the three-dimensional habitat of marine life
}

\author{
Gabriel Jorda $\oplus^{1,2 \star}$, Núria Marbà $\oplus^{1}$, Scott Bennett', Julia Santana-Garcon ${ }^{1}$ ', Susana Agusti $\odot^{3}$ and \\ Carlos M. Duarte ${ }^{3}{ }^{3}$
}

\begin{abstract}
Vertical migration to reach cooler waters is a suitable strategy for some marine organisms to adapt to ocean warming. Here, we calculate that realized vertical isotherm migration rates averaged $-6.6 \pm 18.8 \mathrm{~m} \mathrm{dec}^{-1}$ across the global ocean between 1980 and 2015. Throughout this century (2006-2100), surface isotherms are projected to deepen at an increasing rate across the globe, averaging $-32.3 \mathrm{~m} \mathrm{dec}^{-1}$ under the representative concentration pathway (RCP) 8.5 'business as usual' emissions scenario, and $\mathbf{- 1 8 . 7} \mathrm{m} \mathrm{dec}^{-1}$ under the more moderate RCP4.5 scenario. The vertical redistribution required by organisms to follow surface isotherms over this century is three to four orders of magnitude less than the equivalent horizontal redistribution distance. However, the seafloor depth and the depth of the photic layer pose ultimate limits to the vertical migration possible by species. Both limits will be reached by the end of this century across much of the ocean, leading to a rapid global compression of the three-dimensional (3D) habitat of many marine organisms. Phytoplankton diversity may be maintained but displaced toward the base of the photic layer, whereas highly productive benthic habitats, especially corals, will have their suitable 3D habitat rapidly reduced.
\end{abstract}

$\mathrm{T}$ he effects of ocean warming on marine life are often summarized as a poleward displacement of their biogeographical ranges, tracking the direction and horizontal velocity of surface isotherms in the ocean ${ }^{1-4}$. The assumption underlying this two-dimensional (2D) depiction of warming effects on marine life is that surface temperature adequately represents the thermal regimes experienced in the upper ocean. However, climate velocity is defined as the rate and direction isotherms shift through space ${ }^{1,2,5}$, including the vertical dimension. Indeed, the upper ocean environment is $3 \mathrm{D}$, with temperature and light, among other key factors, regulating biological activity at depth ${ }^{6}$. Consequently, species abundance and richness decline rapidly with depth ${ }^{7}$.

Ocean warming involves the penetration of excess heat in the water column, which can now be detected to characteristic depths of $700 \mathrm{~m}$ across the upper ocean ${ }^{8}$, thereby affecting horizontal thermal regimes but also those at depth. Indeed, marine species around the United States have shifted their distribution, tracking the velocity of isotherm displacement along both the meridional and depth axes $^{5}$. Similarly, North Sea demersal fish assemblages have shifted their depth distribution downward in response to warming ${ }^{9}$. Hence, there is evidence that options available to marine organisms to respond to warming do not only involve local acclimation or poleward range shift, but also a shift in their $3 \mathrm{D}$ range, to occupy deeper, cooler environments that are closer to their optimal thermal range.

The horizontal velocity of climate change and associated poleward displacement of marine life have already been examined globally ${ }^{1,2,4}$. However, the vertical velocity of climate change with depth has not yet been reported at the global scale. Available evidence from regional studies shows that the vertical velocity of climate change can be pronounced, with thermal envelopes deepening by up to $60 \mathrm{~m} \mathrm{dec}^{-1}$ around the United States 5 . Deepening of vertical distributions by a few metres per year has been proposed as a mechanism that allows marine organisms to keep pace with climate change $^{4}$, analogous to terrestrial organisms increasing elevational ranges $^{10}$ and easier than displacing their horizontal biogeographical ranges over tens of kilometres per decade. However, in the same way that marine organisms encounter limitations to their poleward range displacement in response to climate change, such as the presence of land masses in semi-enclosed seas ${ }^{1,2}$, they can also meet constraints in their capacity to displace their range with depth. The restrictions to the vertical extent of marine organisms include bathymetric boundaries in shallow coastal areas, light limitation for primary producers, depth restrictions of resources and habitat availability, and the presence of shallow oxygen minimum zones for animals ${ }^{11}$. All these factors set restrictions on the depth limit possible for vertical migration as a mechanism to adapt to ocean warming.

Here we examine the realized and projected vertical velocity of climate change across the global ocean through the analysis of vertical isotherm migration rates (VIMs, $\mathrm{m} \mathrm{dec}^{-1}$ ), and discuss the potential impact of depth penetration of warmer regimes on marine life. We do so using an ocean reanalysis available for the period 1958-2015 (ref. ${ }^{12}$ ) and the Coupled Model Intercomparison Project Phase 5 (CMIP5) ensemble of global climate models ${ }^{13}$ available for the period 1950-2100 (thus covering the present and future climate). We then examine evidence for the predicted displacement of the depth ranges of marine species, the constraints limiting vertical displacement and the consequences for the compression of the depth ranges of these species by the end of century under the representative concentration pathway (RCP) 8.5 emission scenario, which most closely represents current business-as-usual emission trajectories, and the RCP4.5 emission scenario, which represents a moderate emissions scenario that is broadly consistent with the Paris Agreement.

\section{Results}

Realized and projected rates of vertical isotherm migration. Realized VIMs in the period 1980-2015 averaged ( \pm s.d.)

'Global Change Research Group, Mediterranean Institute for Advanced Studies, University of the Balearic Islands-Spanish Council for Scientific Research, Esporles, Spain. ${ }^{2}$ Instituto Español de Oceanografía, Centre Oceanogràfic de Balears Moll de Ponent s/n, Palma, Spain. ${ }^{3}$ King Abdullah University of Science and Technology, Red Sea Research Center and Computational Biosciences Research Center, Thuwal, Saudi Arabia. *e-mail: gabriel.jorda@ieo.es 


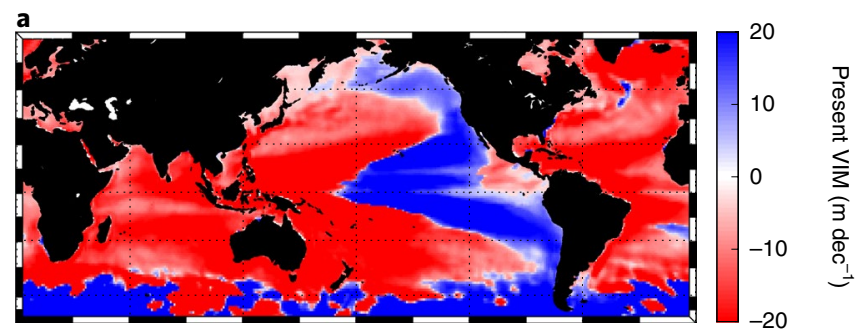

b
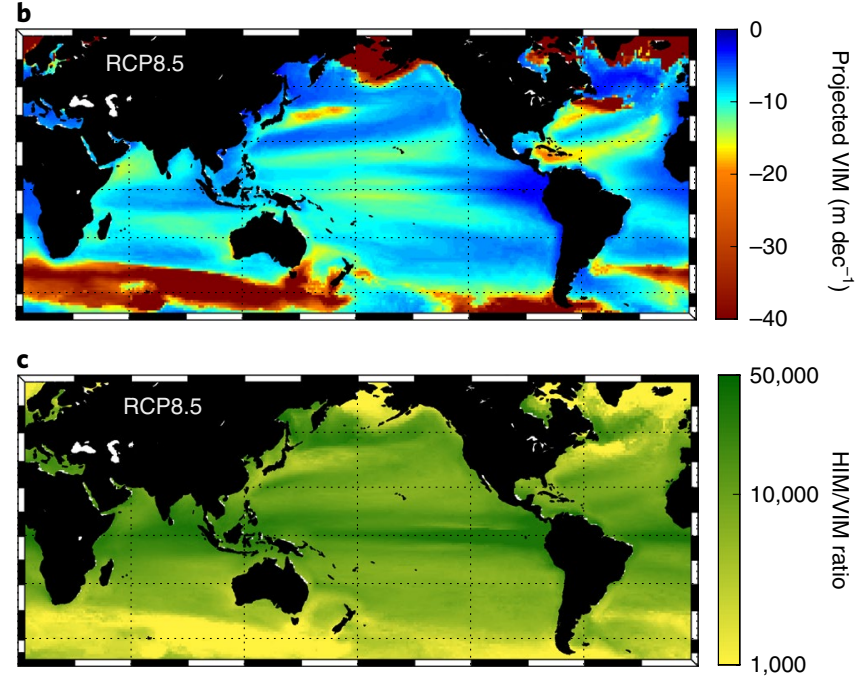

d

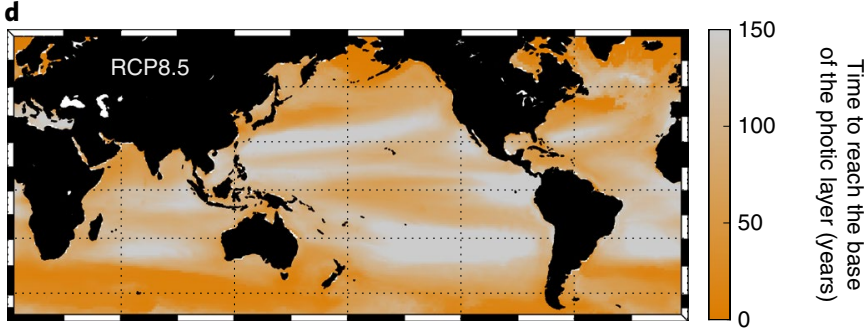

Fig. 1 | Description of isotherm migration. a, Realized VIM rate for the period 1980-2015. b. Projected VIM for the twenty-first century under the RCP8.5 scenario. c, Log ratio of HIM rate over VIM. d, Time estimated for the present sea surface temperature to reach the base of the photic layer across the ocean.

$-6.6+18.8 \mathrm{~m} \mathrm{dec}^{-1}$, ranging from deepening surface isotherms at $-\overline{17} .7 \pm 7.8 \mathrm{~m} \mathrm{dec}^{-1}$ across $69.9 \%$ of the ocean surface, to rising isotherms at $19.4+7.7 \mathrm{~m} \mathrm{dec}^{-1}$ leading to surface cooling across $30.1 \%$ of the ocean surface (Fig. 1a). These large values in recent decades are induced by a combination of global warming and natural climate oscillations (El Niño-Southern Oscillation, or ENSO). Under a business-as-usual scenario, projected VIMs for the period 2006-2100 average $-32.3 \mathrm{~m} \mathrm{dec}^{-1}$, with negative velocities occurring throughout the global ocean, ranging from $-3.8 \mathrm{~m} \mathrm{dec}^{-1}$ to more than $-40 \mathrm{~m} \mathrm{dec}^{-1}$ along the Antarctic Circumpolar Current (Fig. 1b). Under a moderate emissions scenario (RCP4.5), the global average VIM is projected to be $-18.7 \mathrm{~m} \mathrm{dec}^{-1}$, with values ranging from $-2.6 \mathrm{~m} \mathrm{dec}^{-1}$ to more than $-30 \mathrm{~m} \mathrm{dec}^{-1}$ (Extended Fig. 1). These results reflect the fact that average temperatures along the twenty-first century will be warmer, even if experiencing oscillations, than those observed at the end of twentieth century. Projected fast VIM hotspots are prevalent in both polar oceans as well as ocean regions adjacent to major current systems, such as the Gulf Stream and the Kuroshio Current (Fig. 1b). The slowest VIM values are projected to extend offshore of the major eastern boundary upwelling regions, both in the east Pacific and east Atlantic (Fig. 1b), a feature that is conserved across most global climate models (Supplementary Fig. 1).

The spatial patterns of VIMs reflect the combination of warming patterns (Extended Fig. 2a) and the pattern of thermal vertical gradients (Extended Fig. 2b). High VIM values in the Southern Ocean and the tropical Pacific are mainly induced by the relatively low vertical temperature gradients (that is, a long distance must be travelled in the vertical to compensate for the surface warming). Conversely, the high VIM values adjacent to major current systems are driven by higher than average warming rates. The projected depth penetration is consistent across all the isotherms examined, with the $30^{\circ} \mathrm{C}$ isotherm-approaching the thermal limits of corals and other tropical organisms vulnerable to warming-spreading and deepening fast across the tropical and subtropical ocean (Extended Data Fig. 3). VIM rates are projected to be fastest in the Eastern Siberian Sea and central Arctic large marine ecosystems (Supplementary Table 1). The ratio of projected horizontal isotherm migration (HIM, $\mathrm{m} \mathrm{dec}^{-1}$ ) to VIM under RCP8.5 averaged 5,900:1, and ranged from about 1,000:1 to about 30,000:1. The lowest ratios are at high latitude (Fig. 1c), where VIM is fastest and HIM slowest (Extended Data Fig. 4). HIM/VIM ratios under RCP4.5 are similar to those obtained under RCP8.5 due to a similar reduction in both HIM and VIM rates under moderate emissions scenarios (Extended Data Fig. 4).

Based on projected VIMs under RCP8.5 and assuming the depth of the photic layer remains unchanged (Supplementary Fig. 2), present thermal regimes at the surface will reach the base of the photic layer within $87.1 \pm 46.9$ years, ranging from 5 to 10 years in the polar regions and north to the Kuroshi Current and Gulf Stream to 140 years in the centre of the subbasins at subtropical latitudes (Fig. 1d). Under RCP4.5, the time required to reach the base of the photic layer is $130.1+51.1$ years (Extended Data Fig. 1 b). This provides an indication of the future compression of the $3 \mathrm{D}$ habitats of photosynthetic organisms that are currently challenged by surface thermal regimes.

Implications for 3D habitat compression. Two-dimensional analyses of the response of marine life to ocean warming (for example, Poloczanska et al. ${ }^{4}$, Thomas et al. ${ }^{14}$, Jordà et al..$^{15}$ and Garciá-Molinos et al. ${ }^{16}$ ) often ignore the possibility that organisms may find refuge at depth, although this possibility has been acknowledged ${ }^{17}$. For instance, some works predicted a major reduction in phytoplankton potential diversity at low latitudes and an increase in diversity at high latitudes ${ }^{14}$, but their $2 \mathrm{D}$ approach has assumed the surface temperature regime to apply throughout the photic layer that phytoplankton occupy. Combining the model applied by Thomas et al. ${ }^{14}$ with the depth-resolved projected thermal regimes reported here, we show that phytoplankton can find refugia within the deep, cooler photic layer of the subtropical and tropical ocean (Extended Data Fig. 5), resulting in relatively conserved phytoplankton diversity (Fig. 2a and Extended Data Fig. 6). However, this requires a downward migration of species in those regions by, on average, $-9.6 \pm 6.4 \mathrm{~m}$ by 2100 under scenario RCP8.5 and $-4.7+3.0 \mathrm{~m}$ under scenario RCP4.5. Indeed, whereas the potential diversity of polar phytoplankton increases (Fig. 2a), phytoplankton diversity in subtropical and tropical phytoplankton is largely conserved, but the habitat retaining this diversity is compressed toward the base of the photic layer (Fig. 2b). This is consistent with projections of the effect of warming of the subtropical and tropical ocean on picophytoplankton communities, which predict a redistribution toward increased abundance near the base of the photic layer ${ }^{18}$.

Highly productive benthic habitats (for example, seagrasses, corals and kelps) also have high light requirements and, therefore, face vertical compression of their available habitats when surface isotherms exceeding their upper thermal limits move down toward the 
maximum depth limits of the foundation species (Fig. 3, Extended Data Fig. 7 and Extended Data Fig. 8). Hence, the habitats suitable for supporting kelps (thermal limit of $\sim 26^{\circ} \mathrm{C}$; ref. ${ }^{19}$ ), seagrasses (thermal limit of $\sim 25-36^{\circ} \mathrm{C}$, depending on latitude (Marbà, $\mathrm{N}$. et al., manuscript in preparation)), tropical corals (thermal limit of $\sim 30^{\circ} \mathrm{C}$; ref. ${ }^{20}$ ) and their associated fish and invertebrate species are also projected to become increasingly compressed toward their depth limit, as shallow populations will be increasingly exposed to thermal regimes above their tolerance limits (Extended Data Figs 7 and 8). Depth compression of organisms occupying benthic habitats is of particular concern as it also involves a $2 \mathrm{D}$ compression of the habitat. This is because these organisms-unlike pelagic speciescannot occupy the full 3D extent of the water column since the area they potentially occupy is progressively pushed downslope. The projected timeline of habitat loss is particularly severe for tropical corals reefs (Fig. 3). For example, about $50 \%$ of habitat in the Coral Triangle is predicted to be lost by 2025 under a business-as-usual scenario (Extended Data Fig. 9), consistent with observed rates of coral loss over the past decade ${ }^{21}$. Seagrasses and kelps are approaching their thermal limits in some regions $\mathrm{s}^{22}$ and are being increasingly impacted by marine heatwaves (see, for example, Wernberg et al. ${ }^{19}$, Marbà and Duarte ${ }^{23}$ and Arias-Ortiz et al. ${ }^{24}$ ). They are also lightlimited toward their poleward distributional limit where thermally suitable habitats (those in which minimum temperatures are above the species' lower thermal limit) are in deep layers. Nevertheless, seagrasses and kelps are expected to expand poleward to meet suitable thermal regimes and ice loss ${ }^{25}$.

Consistently, under RCP8.5, our results show a potential habitat extension toward polar regions of $3.3 \%$ and $11.0 \%$ for seagrasses and kelps, respectively, which would partially compensate their projected habitat extension loss in warm regions of $-8.6 \%$ and $-20.6 \%$ in 2100, respectively (Fig. 3). However, tropical corals are generally limited to waters with minimum temperatures $>16-20^{\circ} \mathrm{C}$, with a characteristic minimum temperature threshold of $18^{\circ} \mathrm{C}$ (ref. ${ }^{26}$ ) and may, therefore, expand poleward ${ }^{4}$ where suitable light conditions are found ${ }^{26}$. A detailed assessment of potential locations where coral could establish would require an analysis of bottom substrates, but our models provide a first idea of potential expansion. In particular, they predict a $7.0 \%$ habitat expansion of suitable coral reef habitat poleward of their current range in response to ocean warming as the $18^{\circ} \mathrm{C}$ minimum monthly temperature isotherm will penetrate to depths that receive sufficient light to support coral growth. Similar results but at reduced rates are found under RCP4.5 (Fig. 3 and Extended Data Fig. 9).

Consistency of realized rates of vertical velocity with reported changes in depth distributions of marine organisms. The prediction that mortality associated with warming will compress the $3 \mathrm{D}$ extent of marine habitats (Fig. 3) is consistent with the reported effects of marine heatwaves on the mortality of vulnerable benthic organisms (Supplementary Table 2). Seagrass mass mortality events during the past decade have involved the upper depth range of the affected meadows (Supplementary Table 2), ranging from diebacks above $1 \mathrm{~m}$ depth in Chesapeake $\mathrm{Bay}^{27}$ and Florida $\mathrm{Bay}^{28}$ in the United States, where depth limits are confined by shallow photic layers or bathymetry, respectively, to diebacks penetrating to $15 \mathrm{~m}$ and $25 \mathrm{~m}$ depth in Shark Bay in Western Australia (for example, the 2011 heatwave $\mathrm{e}^{24,29}$ ) and the Balearic Islands in the Mediterranean (for example, the 2003 heatwave ${ }^{23}$ ). The 2003 western Mediterranean marine heatwave was also reported to cause diebacks of soft corals to $25-40 \mathrm{~m} \mathrm{depth}{ }^{30}$, and the 2011 Western Australia 2011 marine heatwave caused mass mortality of kelps to $30 \mathrm{~m} \mathrm{depth}{ }^{19}$. While kelps in Western Australia live to depths of $\sim 60 \mathrm{~m}$ (ref. ${ }^{31}$ ), the state of deeper populations in heatwave-affected areas remains unclear.

Reports of coral bleaching and associated mortality during heatwaves, such as the 2015-2016 global mortality event ${ }^{21}$, have
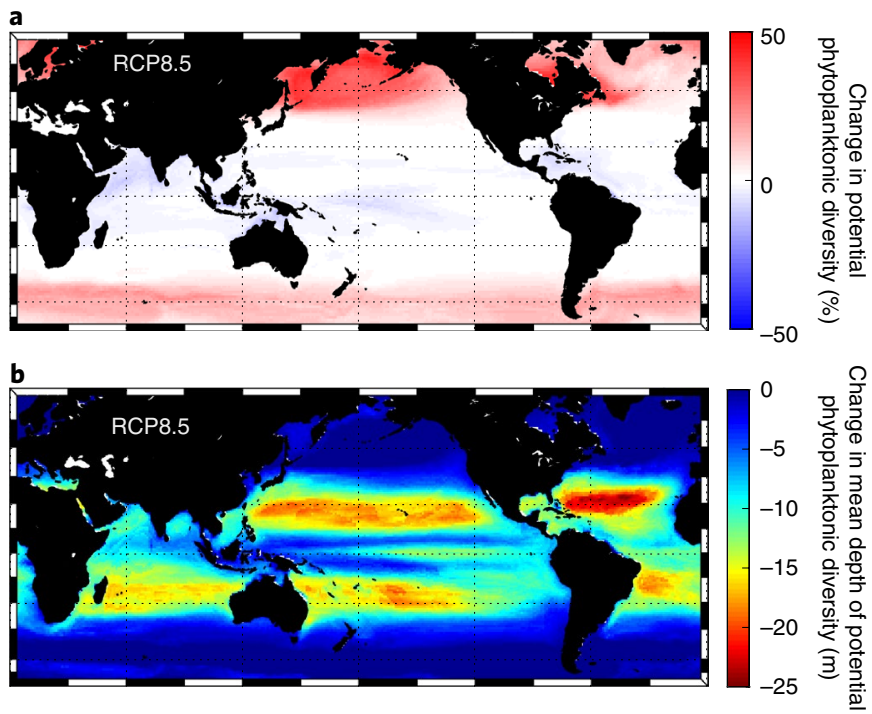

Fig. 2 | Changes in potential phytoplankton diversity under the RCP8.5 emissions scenario. a, Percentage change in potential diversity between historical and projected future temperature regimes considering 3D habitats. b, Change in the mean depth of potential phytoplankton communities between the present (1980-2005) and the end of the twenty-first century (2075-2100).

predominantly focused on shallow reefs and little reference has been made to the condition of deeper habitats ${ }^{21,32}$. Similarly, 2D projections of future thermal stress for the world's coral reefs predict more frequent mass bleaching events $\mathrm{s}^{33}$ but do not address the depth penetration of thermal regimes causing coral mortality. Where bleaching events on corals have been observed across a depth gradient, bleaching rates were generally lower on deep reefs compared to shallow reefs, despite thermal stress causing pronounced coral mortality down to depths of $40 \mathrm{~m}$ (ref. ${ }^{34}$ ). Depth refuges on Australia's Great Barrier Reef were observed to be temporarily constrained by warm water penetrating to greater depths in some years, resulting in thermal bleaching. Moreover, lower diversity on mesophotic reefs suggests that depth refuges may not support as many species as currently observed in shallow environments ${ }^{34}$. Nevertheless, as isotherms penetrate deeper, these findings do broadly support the role of depth as a refuge for coral reefs, analogous to existing evidence of long-term poleward expansion of tropical reefs at $14 \mathrm{~km} \mathrm{year}^{-1}$ in $\operatorname{Japan}^{35,36}$ and eastern ${ }^{37}$ and western Australia ${ }^{38}$.

There are, however, limitations to using the impacts of recent heatwaves as proxies of organismal responses to gradual future warming. Extreme events such as heatwaves sieve populations, removing the most heat-sensitive genotypes and leading to surviving populations that are better adapted to warmer regimes. Currently, long-term adaptation is poorly represented in projections of climate change impacts ${ }^{39,40}$. Evidence from long-term time series of phytoplankton ${ }^{41}$ and laboratory experiments on phytoplankton $^{42,43}$ and corals ${ }^{44}$ suggests that acclimation and genetic adaptation to gradual warming may be possible for some vulnerable populations. However, laboratory experiments on adaptation of short-lived phytoplankton species to warming have also shown that adaption comes with trade-offs that may affect the performance of the adapted population ${ }^{43}$.

The vertical isotherm migration hotspots identified encompass important regions for biodiversity and climate change. For example, vertical isotherms in the Coral Triangle are projected to deepen by ca. $30-40 \mathrm{~m} \mathrm{dec}^{-1}$ (Fig. $1 \mathrm{~b}$ and Extended Data Figs 7 and 8). This region is a global hotspot for biodiversity ${ }^{45}$ and is vulnerable to 

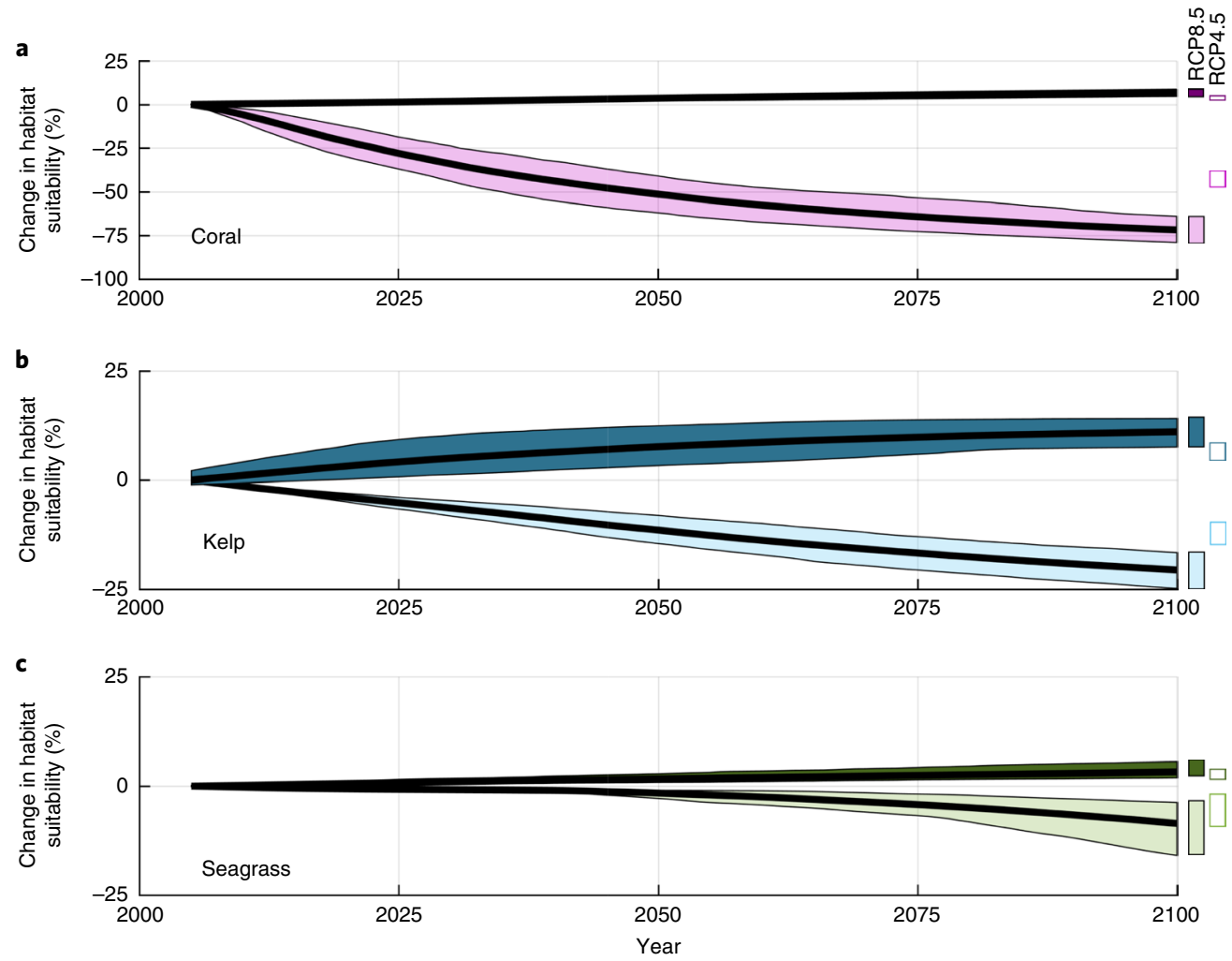

Fig. 3 | Changes in the suitable habitats for benthic organisms. a-c, Light colours show the projected change of present suitable habitats for corals (a), kelps (b) and seagrasses (c) due to compression of 3D habitats during the twenty-first century (expressed as a percentage of present conditions) under the RCP8.5 scenario. Dark colours show the percentage of new suitable habitat for these benthic organisms that will appear as a result of global warming in areas that are currently too cold to support them. The bars at the right express the range of values for scenarios RCP8.5 and RCP4.5. Note the different vertical axes in each panel.

warming, with species living close to their thermal limits ${ }^{46}$ and current warming rates of $0.09-0.12{ }^{\circ} \mathrm{C} \mathrm{dec}^{-1}$. The vulnerability of organisms in the Coral Triangle is evidenced by severe coral bleaching in the past 2 years (ref. ${ }^{32}$ ). Our results suggest that potential depth refugia for organisms in this region may be ephemeral due to fast isotherm deepening rates. Indeed, the $30^{\circ} \mathrm{C}$ isotherm is projected to reach the depth limit of suitable coral habitat by 2040, on average, in this region (Fig. 1d, Extended Data Figs 7 and 8). Eastern continental margins of Australia, South America and southern Africa also represent hotspots of vertical isotherm migration. Fast deepening rates in these regions coincide with strong poleward-flowing boundary currents, with the capacity to facilitate horizontal migration of species ${ }^{47}$. The potential for poleward horizontal migration in these regions may, therefore, offset the physiological challenges associated with vertical migration (for example, light, hydrostatic pressure and oxygen-limitation capacity). At the same time, however, the waters of south-eastern Australia are warming four times faster than mean global ocean warming rates ${ }^{48}$, and benthic species living there are already at the poleward edge of the continental land mass and are therefore limited in the habitat available to them for further poleward migration. These species are faced with a double jeopardy as they are unable to respond to climate change through either horizontal or vertical migration.

\section{Discussion}

The results presented here confirm the acknowledged but often overlooked importance of considering the vertical migration of isotherms when evaluating constraints to the capacity of marine life to adapt to surface warming by displacing their range at depth. Hence, current understanding, dominated by $2 \mathrm{D}$ analyses of biotic responses to ocean warming ${ }^{1,4,14,33}$, need be substantially reconsidered when vertical displacement of isotherms is taken into account. For instance, predicted losses of phytoplankton biodiversity in the tropics are not supported when considering the existence of thermal refugia toward the base of the photic layer. However, our analysis points to a rapid global compression of the $3 \mathrm{D}$ habitat of marine organisms associated with photosynthetic habitat-forming benthic organisms. The capacity of these organisms to adapt to warming by vertically displacing their range is constrained by the depth of the photic layer, while bathymetric limits also involve the 2D compression of their range as they are displaced toward deeper waters in response to the vertical migration of suitable isotherms. In addition, the depth penetration of tropical organisms that are expanding their range poleward is also confined by the presence of waters that are cooler than their lower thermal thresholds. This factor also limits the potential depth range occupied by corals expanding into temperate latitudes. Finally, the expansion of the extensive shallow oxygen minimum zones in the ocean also contributes to further compression of the 3D habitat of organisms that are unable to live in hypoxic layers, squeezing them between shoaling oxygen minimum layers (for example, Stamma et al. ${ }^{49}$ ) and deepening isotherms.

Our analysis shows that the depth of the photic layer poses an ultimate limit to the habitat compression possible for photosynthetic marine organisms and associated biota, consistent with available evidence of the depth redistribution of species in response to warming. Projections of vertical isotherm migration rates under a business-as-usual scenario range from $-3.8 \mathrm{~m} \mathrm{dec}^{-1}$ to more than $-40 \mathrm{~m} \mathrm{dec}^{-1}$ and reveal that $50 \%$ of the available $3 \mathrm{D}$ biogenic habitat could be lost within $80-90$ years. As such, depth refugia may provide only a short-term strategy for many species, for which poleward 
migration or rapid thermal adaptation to keep pace with businessas-usual warming rates may be the only option. Moreover, unless phytoplankton communities become dominated by thermally resistant species, there will be a $3 \mathrm{D}$ compression of the habitat available to photosynthetic organisms. In turn, this implies a general reduction in primary production, as light levels decline exponentially with organismal displacement at depth. The prevailing $2 \mathrm{D}$ understanding of the responses of marine life to climate change needs to be expanded to $3 \mathrm{D}$ approaches, integrating the vertical habitat compression of marine organisms with ocean warming. The evidence for ongoing and future widespread 3D habitat compression of marine life represents a major, unrealized impact of climate change on marine ecosystems that requires urgent attention. This should be complemented by studies assessing the capacity for adaptation to new thermal regimes of different species, which can partially counteract the impacts of warming.

\section{Methods}

Data. The characterization of the 3D temperature field for the present climate was carried out using the outputs from the ORAS4 ocean reanalysis system ${ }^{12}$ (available at https://www.ecmwf.int/en/forecasts/datasets/archive-datasets/browse-reanalysisdatasets) for the period 1958-2014. This reanalysis is based on the NEMO ocean model with $1^{\circ}$ of horizontal resolution and 42 vertical levels. The model assimilates in situ temperature and salinity profiles, along-track sea-level anomalies and sea-level trends.

For the projected evolution of the temperature field through the twentyfirst century, we used the outputs from an ensemble of 28 global climate models (Supplementary Fig. 1) from CMIP5 (ref. ${ }^{13}$; available at https://esgf-node.llnl. gov/search/cmip5/) under the RCP8.5 and RCP4.5 scenarios of greenhouse gas emissions. The temperature change projected by each model was computed as the difference between the mean temperature in the periods 2075-2100 and 1980-2005. Then, those anomalies were interpolated to the ORAS4 grid and added to the present temperature from ORAS4 in order to get the projected temperature. This procedure was followed to remove potential biases in the global climate model simulations ${ }^{50}$. For all the diagnostics used in this work, we carried out the computations for each model and then averaged the outputs to get a more robust estimate of the future evolution of the diagnostics.

For the Mediterranean region, additional computations were performed using high-resolution regional reanalysis and regional climate models. The regional reanalysis used here was the Copernicus Marine Environmental Monitoring Service product (https://doi.org/10.25423/medsea_reanalysis_phys_006_004; ref. ${ }^{51}$ ), run at $1 / 16^{\circ}$ of horizontal resolution and 72 vertical levels, and assimilating in situ and satellite observations. The regional climate simulations, all of which had horizontal resolutions higher than $1 / 8^{\circ}$, which is considered to be sufficient to solve the most important processes in the region, were obtained from the Med-CORDEX initiative (https://www.medcordex.eu/) $)^{52}$. The values shown in all the figures for the Mediterranean were obtained from this regional ensemble. Nevertheless, the final results using the high-resolution products did not differ greatly from the global products.

The depth of the base of the photic layer was obtained from SeaWifs satellite images. Monthly estimates (downloaded from https://oceandata.sci.gsfc.nasa.gov/ SeaWiFS/Mapped/Monthly/9km/Zeu_lee) were averaged for the period 1997-2010 to obtain a 12 -month climatology.

The boundaries defining the large marine ecosystems of the world were downloaded from http://lme.edc.uri.edu.

Isotherm migration rates. We computed VIMs to assess the speed at which the present sea surface temperature at a given location deepens due to global warming. To do so, for each location $\left(x_{0}, y_{0}\right)$ we examined the projected 3D temperature field at that location $\left(T^{2100}\left(x_{0}, y_{0}, z\right)\right)$ and extracted the depth at which the present sea surface temperature $\left(x_{0}, y_{0}\right)$ is found $\left(Z_{\text {new }}\right)$ using linear interpolation. Then, VIM (measured in mear $^{-1}$ ) is simply computed as:

$$
\operatorname{VIM}=\left(Z_{\text {new }}\right) /\left(t_{\text {end }}-t_{\text {ini }}\right)
$$

where $t_{\text {end }}$ is year 2100 and $t_{\text {ini }}$ is year 2006. Therefore, VIMs reflect the averaged isotherm migration rate over the period 2006-2100 for each of the two scenarios. The VIM values will depend on the local rate of warming and the shape of the vertical temperature profile. Thus in areas with a strong thermocline one can expect a low VIM, while in regions with a weak thermocline the VIM will be large (that is, the present sea surface temperature will be found at great depths).

We also computed the HIMs (Extended Data Fig. 4). In this case, for a given location $\left(x_{0}, y_{0}\right)$ we looked at the projected sea surface temperature field $\left.\operatorname{SSST}^{2100}(x, y)\right)$ to determine the closest location at which the present sea surface temperature $\left(x_{0}, y_{0}\right)$ is found $\left(x_{\text {new }}, y_{\text {new }}\right)$. The distance is computed as the minimum number of connected pixels between two locations, thus taking into account possible land barriers. Then, HIM (measured in mear $^{-1}$ ) is computed as:

$$
\mathrm{HIM}=d\left(x_{\text {new }}, y_{\text {new }}, x_{0}, y_{0}\right) /\left(t_{\text {end }}-t_{\text {ini }}\right)
$$

where $d\left(x_{\text {new }}, y_{\text {new }}, x_{0}, y_{0}\right)$ is the distance between the new location $\left(x_{\text {new }}, y_{\text {new }}\right)$ and the original location $\left(x_{0}, y_{0}\right)$.

The ratio HIM/VIM (Fig. 1c) provides a measure of the comparison between two strategies for marine organisms to respond to global warming: migration in the horizontal and migration in the vertical. A low HIM/VIM ratio indicates that a short vertical migration implies the same change in the thermal regime as a long horizontal migration. Sensitivity tests were performed to see if VIM or HIM values change depending on the month of the year for which data were used to carry out the computations, but no major differences were found.

Potential diversity of phytoplankton communities. We followed the same approach as Thomas et al. ${ }^{14}$ to estimate the potential diversity of phytoplankton communities. This is not the actual diversity as we do not know the relative abundance of each species in the communities, but the potential diversity based solely on thermal niches. We used the thermal ranges and thermal optimal temperature for individual phytoplankton species provided by Thomas et al. in their supplementary information ${ }^{14}$ to identify the number of phytoplankton species that meet thermal conditions within their thermal range at a particular location, defined here as a $1^{\circ}$ by $1^{\circ}$ cell within an ocean grid. We first did so using present sea surface temperatures, following Thomas et al. ${ }^{14}$, and obtained the same results they show (Extended Data Fig. 5a). We then considered that phytoplankton could establish at any depth inside the photic zone and therefore assessed, using the same approach, the number of phytoplankton species that met temperatures consistent with their thermal tolerance at any depth within the photic zone for each location. Using this 3D approach we found a greater potential phytoplankton diversity in tropical and subtropical regions (Extended Data Fig. 5b) as suitable thermal conditions may not be found in surface waters but may be found in deeper waters within the photic layer. We used the same approach to project future potential diversity, using the projected $3 \mathrm{D}$ temperature field.

We have also computed the average depth of the potential community. To do so, for each phytoplankton species $(k)$ and at each grid point, we computed the depth at which the temperature closest to the species' optimal temperature $\left(Z_{k}^{\text {opt }}\right)$ occurs. Then, we computed the characteristic depth of the potential community as the average of $Z_{k}^{\text {opt }}$ for all the species that meet their thermal range within the photic layer at that location. The global distribution of calculated $Z^{\text {opt }}$ for the present climate is shown in Extended Data Fig. $5 c$, and the projected changes in Fig. $2 \mathrm{~b}$ and Extended Data Fig. 6.

Suitable habitats for benthic organisms. The suitable habitats for benthic organisms were defined using light and temperature criteria ${ }^{53}$. For each group (corals, kelps and seagrasses), the potentially suitable habitat was first defined as those locations at which a certain amount of radiation reaches the bottom. The minimum required radiation for the three groups was set to 1.4, 0.3 and $5.1 \mathrm{~mol}$ photons $\mathrm{m}^{-2} \mathrm{~d}^{-1}$, respectively, which represent the minimum irradiance to support these communities ${ }^{53}$. We then also imposed the condition that the temperature at the bottom should be less than the upper thermal limit of these organisms $\left(30^{\circ} \mathrm{C}\right.$ for tropical corals, $26^{\circ} \mathrm{C}$ for kelps and $25-36^{\circ} \mathrm{C}$, depending on latitude, for seagrasses ${ }^{21}$ ). The use of light and temperature thresholds to define the suitable habitat for benthic organisms delineates a maximum potential extent, as it ignores other limiting factors, such as adequate substrate, for which global distribution is not available. These analyses assume that the depth of the photic layer does not change consistently with warming in the coastal ocean, and while we cannot rule out such changes, recent evidence reports no clear long-term trends ${ }^{54}$.

Reporting Summary. Further information on research design is available in the Nature Research Reporting Summary linked to this article.

\section{Data availability}

All data are available in the main text or the supplementary materials.

Received: 31 January 2019; Accepted: 13 November 2019; Published online: 23 December 2019

\section{References}

1. Burrows, M. T. et al. The pace of shifting climate in marine and terrestrial ecosystems. Science 334, 652-655 (2011).

2. Burrows, M. T. et al. Geographical limits to species-range shifts are suggested by climate velocity. Nature 507, 492-495 (2014).

3. Pörtner, H. O. et al. in Climate Change 2014 Impacts, Adaptation, and Vulnerability (eds Field, C. B. et al.) 411-484 (Cambridge Univ. Press, 2014).

4. Poloczanska, E. S. et al. Global imprint of climate change on marine life. Nat. Clim. Change 3, 919-925 (2013).

5. Pinsky, M. L., Worm, B., Fogarty, M. J., Sarmiento, J. L. \& Levin, S. A. Marine taxa track local climate velocities. Science 341, 1239-1242 (2013). 
6. Gaston, K. J. Global patterns in biodiversity. Nature 405, 220-227 (2000).

7. Brokovich, E., Einbinder, S., Shashar, N., Kiflawi, M. \& Kark, S. Descending to the twilight-zone: changes in coral reef fish assemblages along a depth gradient down to 65 m. Mar. Ecol. Prog. Ser. 371, 253-262 (2008).

8. Rhein, M. et al. in Climate Change 2013: The Physical Science Basis (eds Stocker, T. F. et al.) 255-316 (Cambridge Univ. Press, 2013).

9. Dulvy, N. K. et al. Climate Change and deepening of the North Sea fish assemblage: a biotic indicator of warming seas. J. Appl. Ecol. 45, 1029-1039 (2008)

10. Parmesan, C. \& Yohe, G. A globally coherent fingerprint of climate change impacts across natural systems. Nature 421, 37-42 (2003).

11. Brown, A. \& Thatje, S. The effects of changing climate on faunal depth distributions determine winners and losers. Glob. Change Biol. 21, 173-180 (2015).

12. Balmaseda, M. A., Mogensen, K. \& Weaver, A. T. Evaluation of the ECMWF ocean reanalysis system ORAS4. Q. J. R. Meteorol. Soc. 139, 1132-1161 (2013).

13. Taylor, K. E. et al. An overview of CMIP5 and the experiment design. Bull. Am. Meteorol. Soc. 93, 485-498 (2012).

14. Thomas, M. K., Kremer, C. T., Klausmeier, C. A. \& Litchman, E. A global pattern of thermal adaptation in marine phytoplankton. Science 338, 1085-1088 (2012).

15. Jordà, G., Marbà, N. \& Duarte, C. M. Mediterranean seagrass vulnerable to regional climate warming. Nat. Clim. Change 2, 821-824 (2012).

16. Garciá Molinos, J. et al. Climate velocity and the future global redistribution of marine biodiversity. Nat. Clim. Change 6, 83-88 (2016).

17. Bennett, S. et al. Canopy interactions and physical stress gradients in subtida communities. Ecol. Lett. 18, 677-686 (2015).

18. Agusti, S., Lubián, L. M., Moreno-Ostos, E., Estrada, M. \& Duarte, C. M. Projected changes in photosynthetic picoplankton in a warmer subtropical ocean. Front. Mar. Sci. https://doi.org/10.3389/fmars.2018.00506 (2019).

19. Wernberg, T. et al. Climate-driven regime shift of a temperate marine ecosystem. Science 353, 169-172 (2016).

20. Hoegh-Guldberg, O. Climate change, coral bleaching and the future of the world's coral reefs. Mar. Freshw. Res. 50, 839 (1999).

21. Hughes, T. P. et al. Spatial and temporal patterns of mass bleaching of corals in the Anthropocene. Science 359, 80-83 (2018).

22. Filbee-Dexter, K., Feehan, C. \& Scheibling, R. Large-scale degradation of a kelp ecosystem in an ocean warming hotspot. Mar. Ecol. Prog. Ser. 543, 141-152 (2016).

23. Marbà, N. \& Duarte, C. M. Mediterranean warming triggers seagrass (Posidonia oceanica) shoot mortality. Glob. Change Biol. 16, 2366-2375 (2010)

24. Arias-Ortiz, A. et al. A marine heatwave drives massive losses from the world's largest seagrass carbon stocks. Nat. Clim. Change 8, 338-344 (2018).

25. Krause-Jensen, D. \& Duarte, C. M. Substantial role of macroalgae in marine carbon sequestration. Nat. Geosci. 9, 737-742 (2016).

26. Muir, P. R., Wallace, C. C., Done, T. \& Aguirre, J. D. Coral reefs. Limited scope for latitudinal extension of reef corals. Science 348, 1135-1138 (2015)

27. Moore, K. A. \& Jarvis, J. C. Eelgrass diebacks in the lower chesapeake bay: implications for long-term persistence. J. Coast. Res. 55, 135-147 (2008).

28. Carlson, D. F. et al. Sea surface temperatures and seagrass mortality in Florida Bay: spatial and temporal patterns discerned from MODIS and AVHRR data. Remote Sens. Environ. 208, 171-188 (2018).

29. Thomson, J. A. et al. Extreme temperatures, foundation species, and abrupt ecosystem change: an example from an iconic seagrass ecosystem. Glob. Change Biol. 21, 1463-1474 (2015).

30. Garrabou, J. et al. Mass mortality in northwestern Mediterranean rocky benthic communities: effects of the 2003 heat wave. Glob. Change Biol. 15 , 1090-1103 (2009).

31. Marzinelli, E. M. et al. Large-scale geographic variation in distribution and abundance of australian deep-water kelp forests. PLOS ONE 10, e0118390 (2015)

32. Hughes, T. P. et al. Global warming and recurrent mass bleaching of corals. Nature 543, 373-377 (2017).

33. Lough, J. M., Anderson, K. D. \& Hughes, T. P. Increasing thermal stress for tropical coral reefs: 1871-2017. Sci. Rep. 8, 6079 (2018).

34. Frade, P. R. et al. Deep reefs of the Great Barrier Reef offer limited thermal refuge during mass coral bleaching. Nat. Commun. 9, 3447 (2018).

35. Yamano, H., Sugihara, K. \& Nomura, K. Rapid poleward range expansion of tropical reef corals in response to rising sea surface temperatures. Geophys. Res. Lett. 38, L04601 (2011).

36. Takao, S. et al. An improved estimation of the poleward expansion of coral habitats based on the inter-annual variation of sea surface temperatures. Coral Reefs 34, 1125-1137 (2015).

37. Baird, A. H., Sommer, B. \& Madin, J. S. Pole-ward range expansion of Acropora spp. along the east coast of Australia. Coral Reefs 31, 1063-1063 (2012).
38. Tuckett, C. A., de Bettignies, T., Fromont, J. \& Wernberg, T. Expansion of corals on temperate reefs: direct and indirect effects of marine heatwaves. Coral Reefs 36, 947-956 (2017).

39. Visser, M. E. Keeping up with a warming world; assessing the rate of adaptation to climate change. Proc. R. Soc. B 275, 649-659 (2008).

40. Bennett, S., Duarte, C. M., Marbà, N. \& Wernberg, T. Integrating withinspecies variation in thermal physiology into climate change ecology. Philos. Trans. R. Soc. B 374, 20180550 (2019).

41. Irwin, A. J., Finkel, Z. V., Müller-Karger, F. E. \& Troccoli Ghinaglia, L. Phytoplankton adapt to changing ocean environments. Proc. Natl Acad. Sci. USA 112, 5762-5766 (2015).

42. Padfield, D., Yvon-Durocher, G., Buckling, A., Jennings, S. \& Yvon-Durocher, G. Rapid evolution of metabolic traits explains thermal adaptation in phytoplankton. Ecol. Lett. 19, 133-142 (2016).

43. Jin, P. \& Agustí, S. Fast adaptation of tropical diatoms to increased warming with trade-offs. Sci. Rep. 8, 17771 (2018).

44. Matz, M. V., Treml, E. A., Aglyamova, G. V. \& Bay, L. K. Potential and limits for rapid genetic adaptation to warming in a Great Barrier Reef coral. PLoS Genet. 14, e1007220 (2018).

45. Bellwood, D. R. \& Hughes, T. P. Regional-scale assembly rules and biodiversity of coral reefs. Science 292, 1532-1535 (2001).

46. Stuart-Smith, R. D., Edgar, G. J., Barrett, N. S., Kininmonth, S. J. \& Bates, A. E. Thermal biases and vulnerability to warming in the world's marine fauna. Nature 528, 88-92 (2015).

47. Vergés, A. et al. The tropicalization of temperate marine ecosystems: climate-mediated changes in herbivory and community phase shifts. Proc. Biol. Sci. 281, 20140846 (2014).

48. Hobday, A. J. \& Lough, J. M. Projected climate change in Australian marine and freshwater environments. Mar. Freshw. Res. 62, 1000 (2011).

49. Stramma, L. et al. Expansion of oxygen minimum zones may reduce available habitat for tropical pelagic fishes. Nat. Clim. Change 2 33-37 (2012).

50. Collins, M. et al. in Climate Change 2013: The Physical Science Basis (eds. Stocker, T. F. et al.) 1029-1136 (Cambridge Univ. Press, 2013).

51. Simoncelli, S. et al. Mediterranean Sea Physical Reanalysis (MEDREA 1987-2015) Version 1 (Copernicus Marine Environment Monitoring Service, 2014); https://doi.org/10.25423/medsea_reanalysis_phys_006_004

52. Ruti, P. M. et al. Med-CORDEX initiative for mediterranean climate studies. Bull. Am. Meteorol. Soc. 97, 1187-1208 (2016).

53. Gattuso, J.-P. et al. Light availability in the coastal ocean: Impact on the distribution of benthic photosynthetic organisms and their contribution to primary production. Biogeosciences 3, 489-513 (2006).

54. Dutkiewicz, S. et al. Ocean colour signature of climate change. Nat. Commun 10, 578 (2019)

\section{Acknowledgements}

We thank the World Climate Research Programme for producing and making available the CMIP5 model output. This research has been partially funded by Spanish Projects CLIFISH (grant no. CTM2015-66400-C3-2-R), MedSHIFT (grant no. CGL201571809-P), Fundación BBVA (Interbioclima project), European Union's Horizon 2020 SOCLIMPACT project (grant agreement no. 776661) and King Abdullah University of Science and Technology through baseline funding to C.M.D and S.A. S.B. received funding from the European Union's Horizon 2020 research and innovation programme (grant agreement no. 65924). J.S.G. was supported by a Juan de la Cierva Formación contract from the Spanish Ministry of Economy, Industry and Competiveness.

\section{Author contributions}

G.J., C.M.D., N.M., S.B. and S.A. conceived of the study. S.A., N.M., S.B. and J.S.-G. collected the data. G.J. was responsible for computation and formal analysis. C.M.D., G.J., N.M., S.A., S.B. and J.S.-G. wrote and reviewed the manuscript.

\section{Competing interests}

The authors declare no competing interests.

\section{Additional information}

Extended data is available for this paper at https://doi.org/10.1038/s41559-019-1058-0.

Supplementary information is available for this paper at https://doi.org/10.1038/ s41559-019-1058-0.

Correspondence and requests for materials should be addressed to G.J.

Reprints and permissions information is available at www.nature.com/reprints.

Publisher's note Springer Nature remains neutral with regard to jurisdictional claims in published maps and institutional affiliations.

(c) The Author(s), under exclusive licence to Springer Nature Limited 2019 

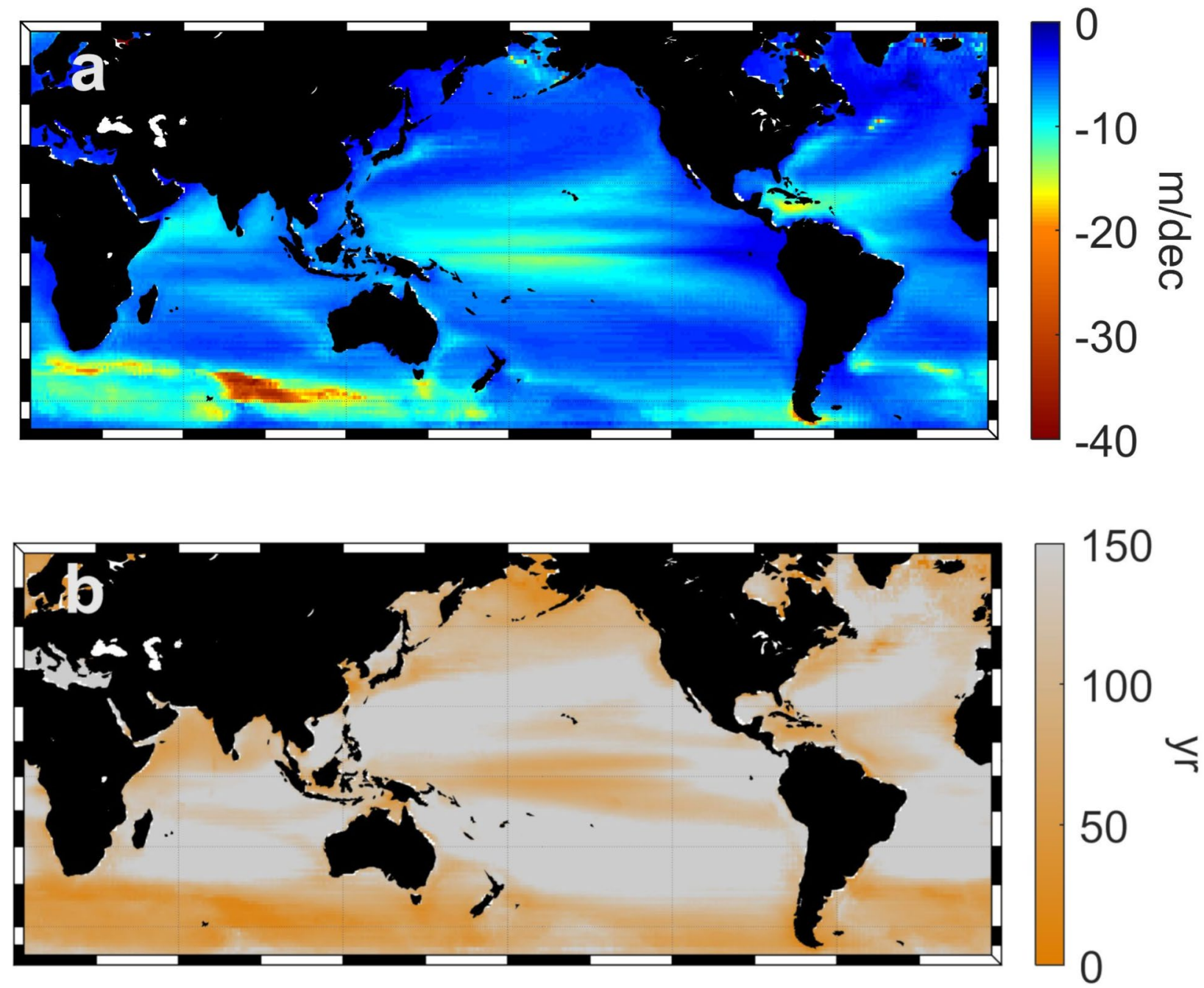

Time to the reach the base of the photic layer under RCP4.5

Extended Data Fig. 1 | Description of isotherm migration under a moderate scenario. a, Projected VIM (m/dec) for the 21stcentury under the RCP4.5 scenario. $\mathbf{b}$, Time estimated for the present sea surface temperature to reach the base of the photic layer across the ocean (in years). 

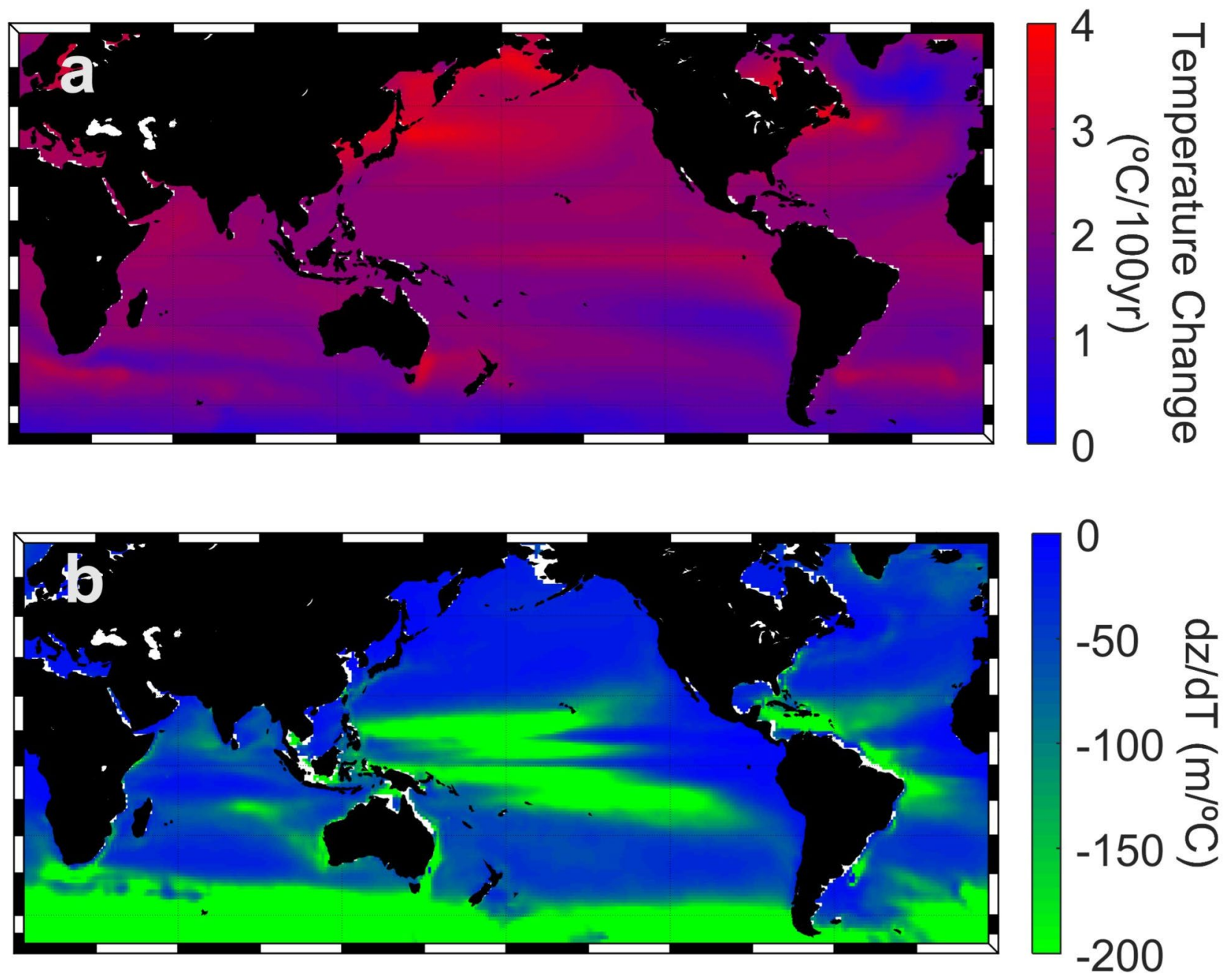

Extended Data Fig. 2 | Ensemble average of the contributors to VIM. a, Sea surface temperature change under the RCP8.5 scenario (in ㄷ/100 yr). b, Projection of the inverse of the temperature gradient (in $\mathrm{m} /{ }^{\circ} \mathrm{C}$ ) for 2100 under the RCP8.5 scenario. 

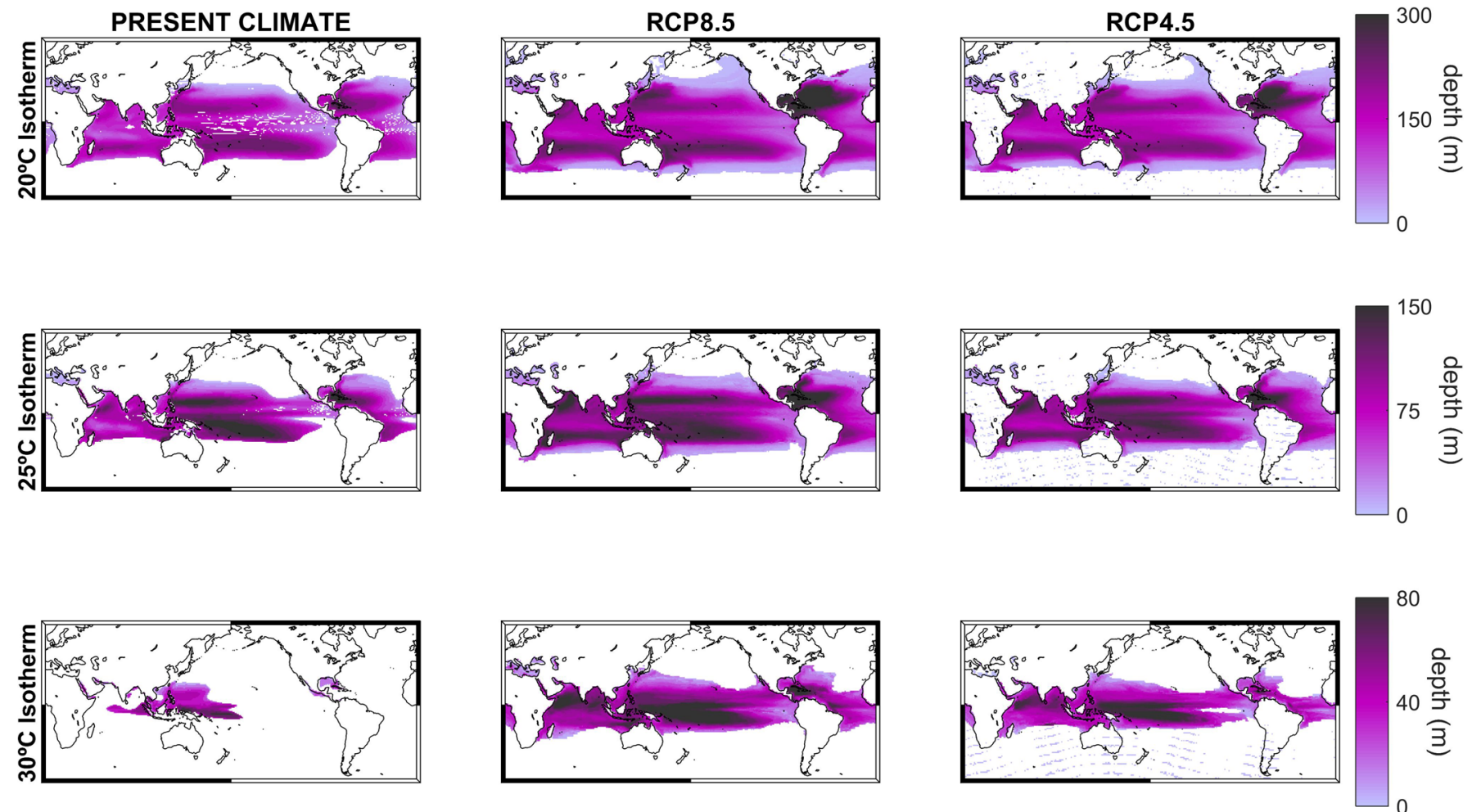

Extended Data Fig. 3 | Depth of key isotherms. The depth (in m) at which the $20^{\circ} \mathrm{C}$ (top), $25^{\circ} \mathrm{C}$ (middle) and $30^{\circ} \mathrm{C}$ (bottom) isotherms are found in the present climate (left column) and in the projected future climate by 2100 under scenario RCP8.5 (middle column) and scenario RCP4.5 (right column). The summer temperature is used. 

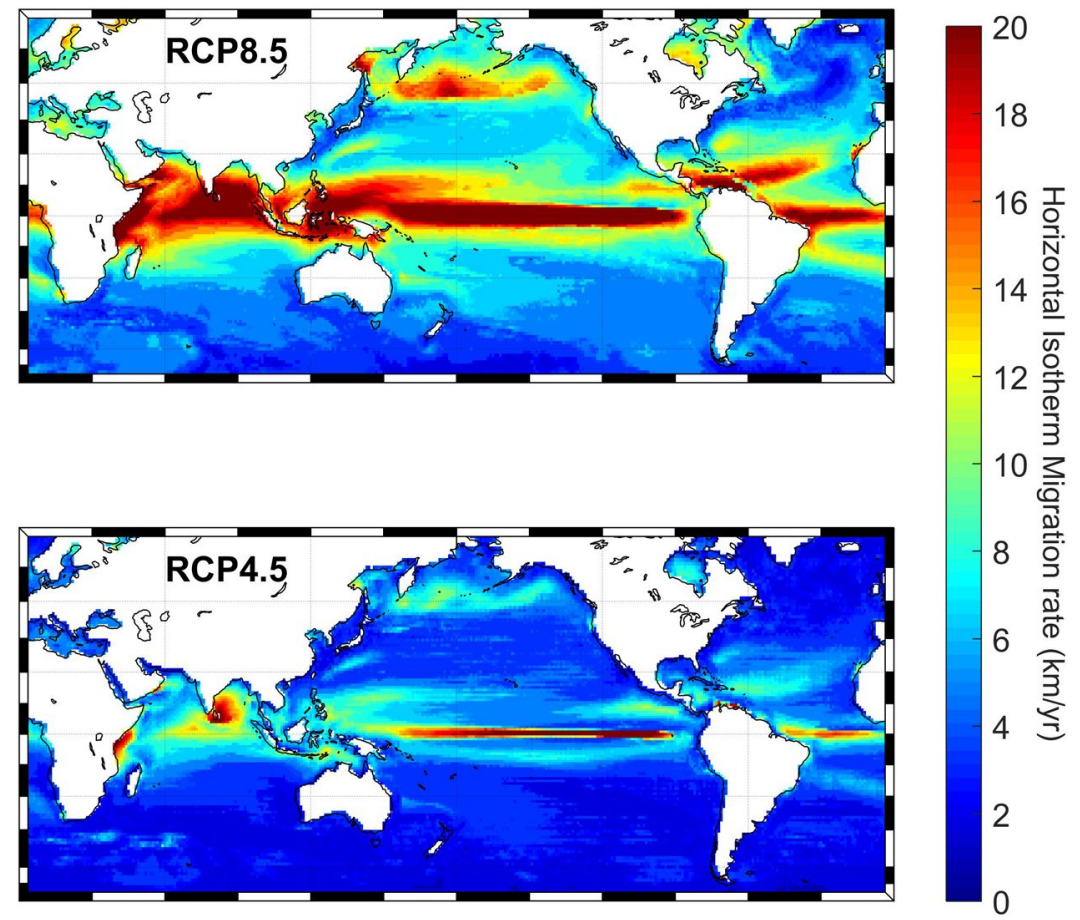

Extended Data Fig. 4 | Horizontal Isotherm Migration rates. Averaged over all the GCMs under (a) the RCP8.5 scenario and (b) the RCP4.5 scenario. 

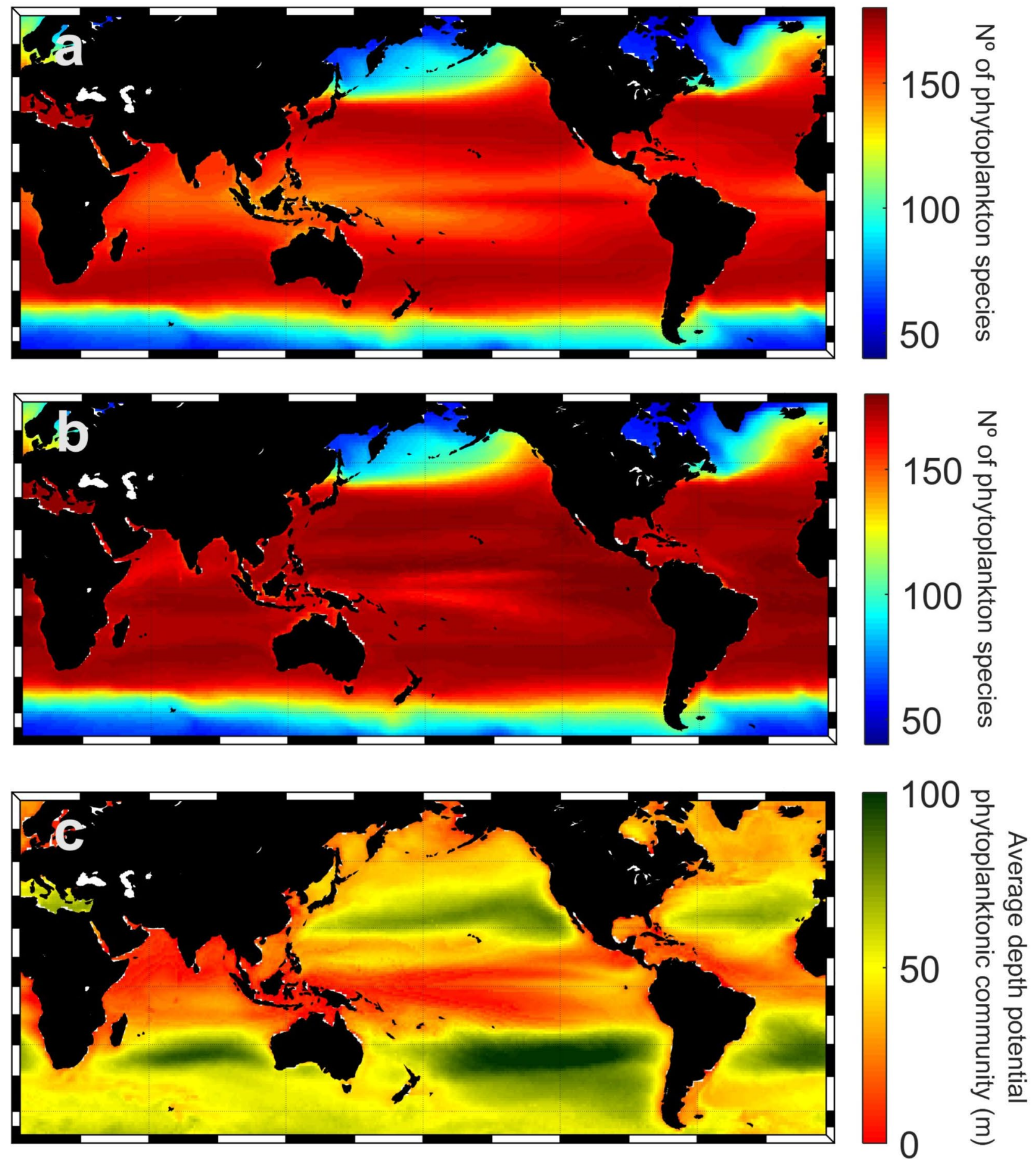

Extended Data Fig. 5 | Potential Phytoplankton diversity. a, Number of phytoplankton species for which the present annual averaged Sea Surface Temperature fits into their thermal range. $\mathbf{b}$, Number of phytoplankton species for which a temperature in the photic layer fits into their thermal range. c, Averaged depth for the potential phytoplankton community under present climate conditions. 

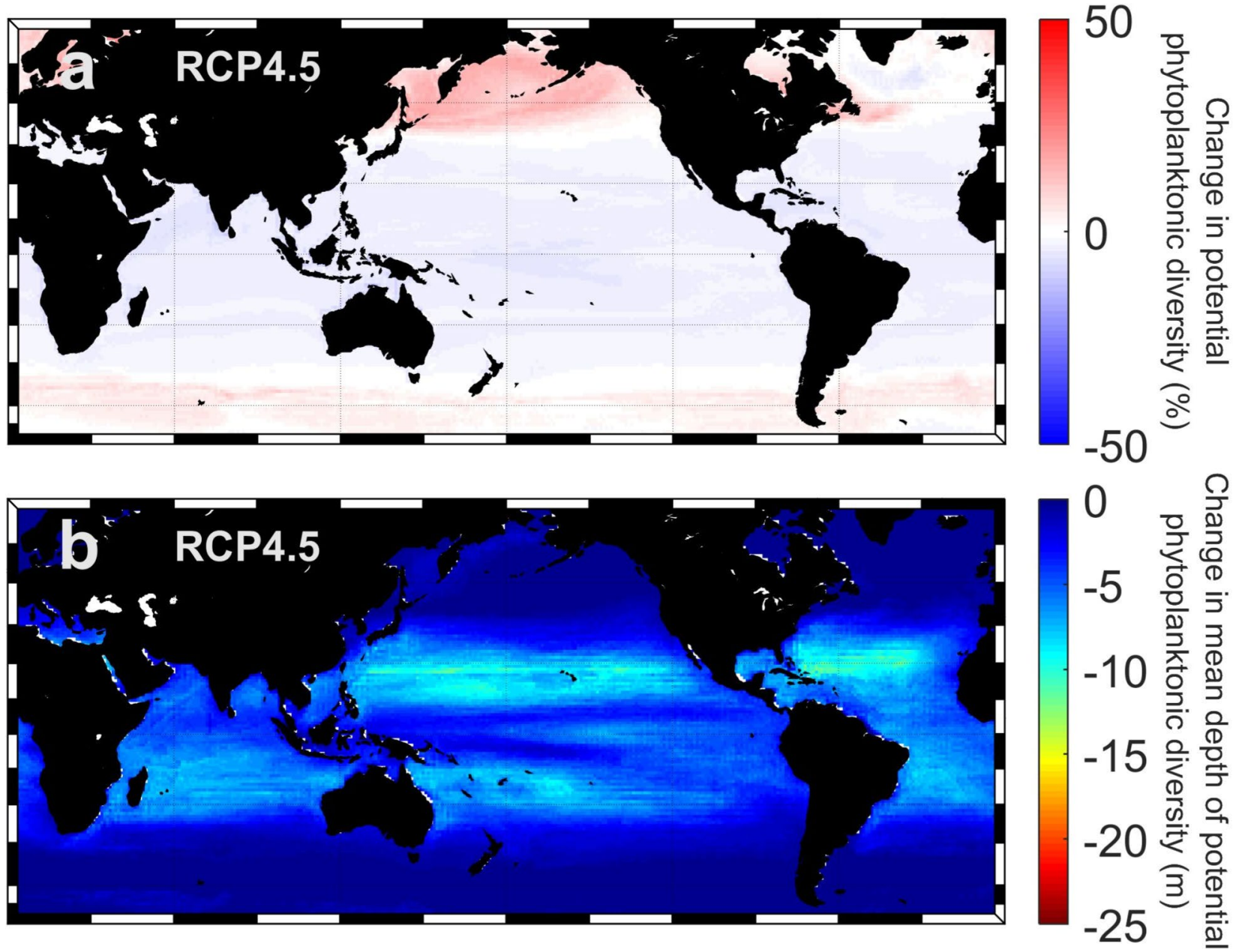

Extended Data Fig. 6 | Changes in potential phytoplankton diversity under a moderate scenario (RCP4.5). a, Percent change in potential diversity between historical and projected future temperature regimes considering 3-D habitats. $\mathbf{b}$, Change in the mean depth (in meters) of potential phytoplankton communities between present (1980-2005) and end of the 21st century (2075-2100). 

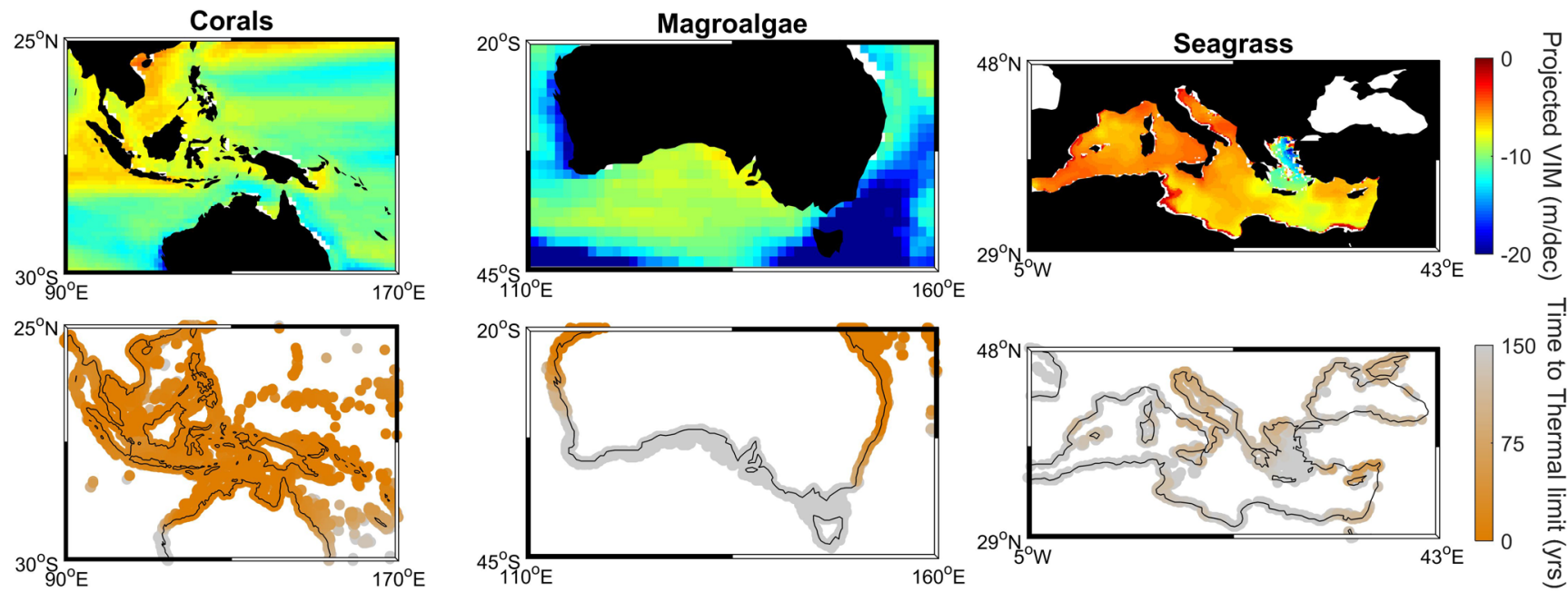

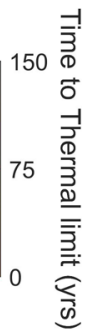
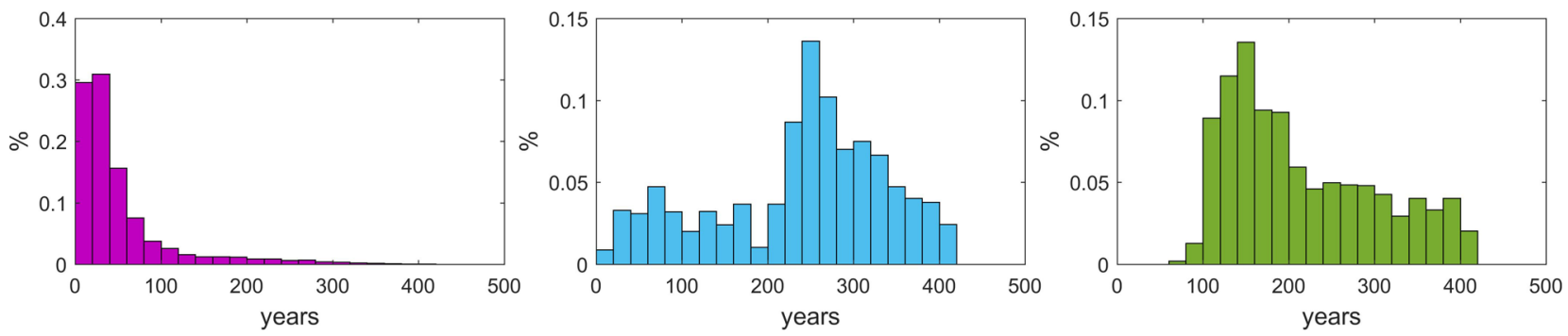

Extended Data Fig. 7 | Vulnerability of benthic organisms under a business as usual scenario. Several diagnostics for Corals (Left column), Kelps (Middle column) and Seagrasses (Right column) under the RCP8.5 scenario: Zoom on the vertical isotherm migration rates (Top row); Time required to reach the upper thermal limit in the current suitable habitats (Middle row); Histogram of those values (Bottom row). 

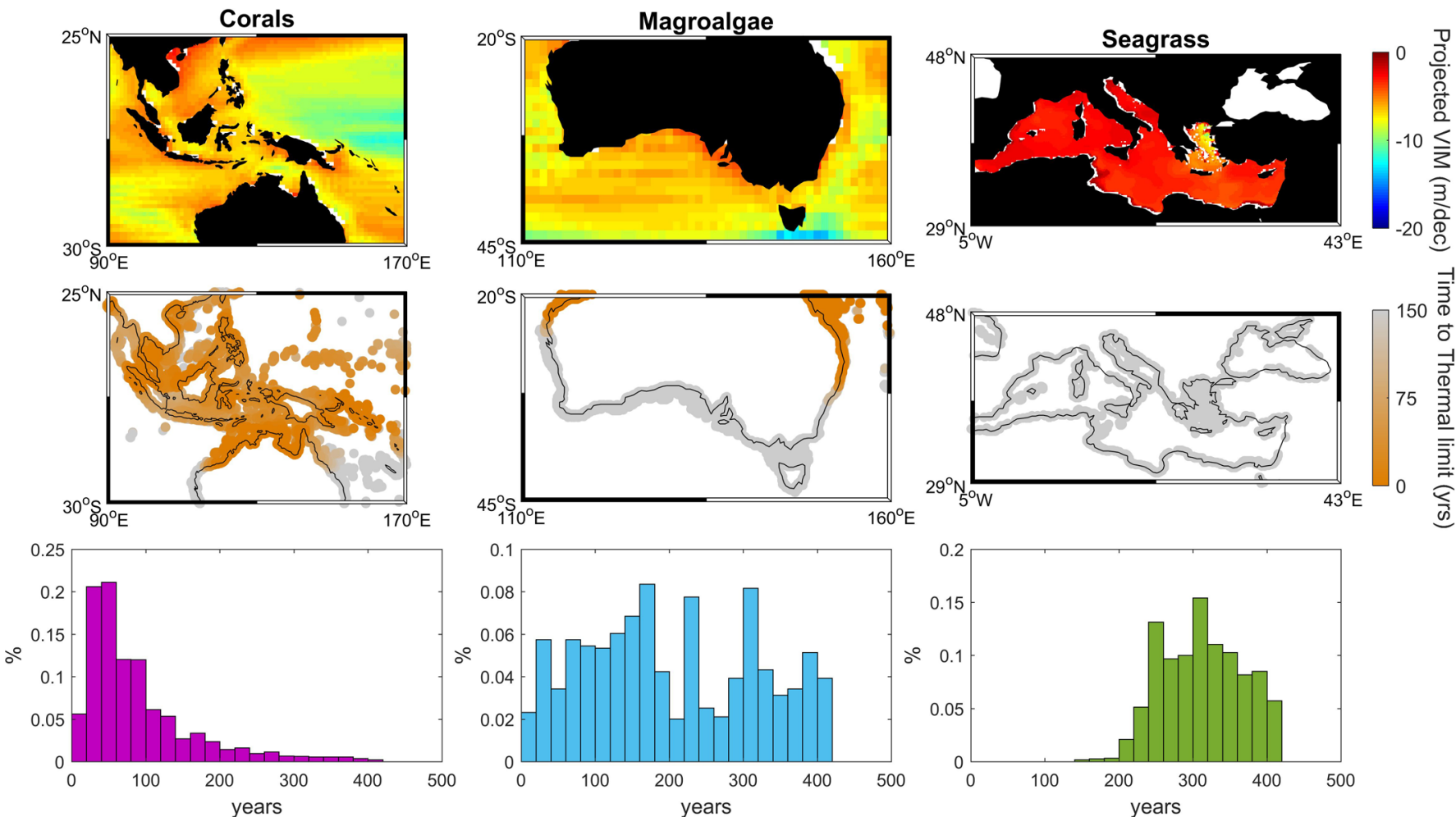

Extended Data Fig. 8 | Vulnerability of benthic organisms under a moderate scenario. Several diagnostics for Corals (Left column), Kelps (Middle column) and Seagrasses (Right column) under the RCP4.5 scenario: Zoom on the vertical isotherm migration rates (Top row); Time required to reach the upper thermal limit in the current suitable habitats (Middle row); Histogram of those values (Bottom row). 

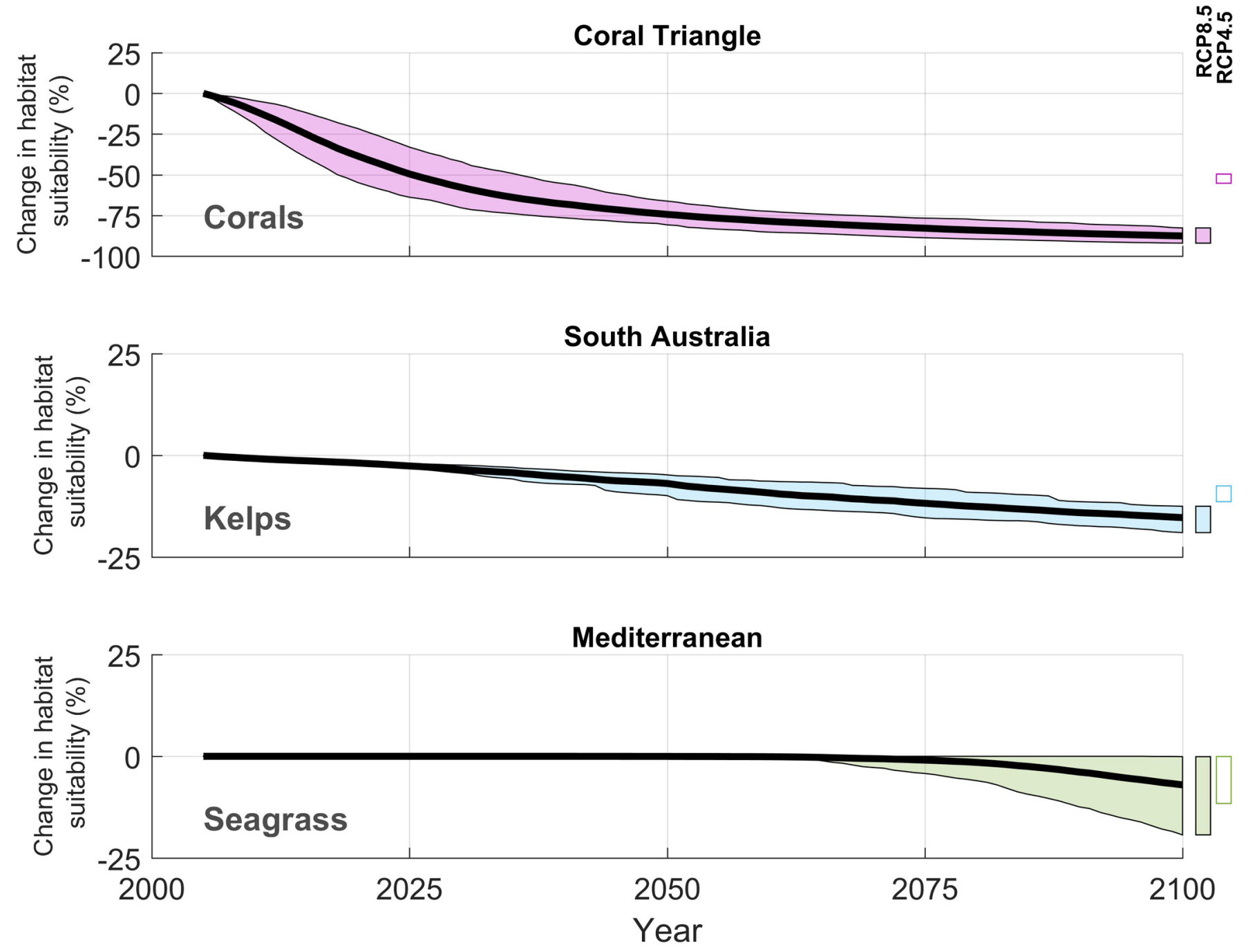

Extended Data Fig. 9 | Changes in the suitable habitats for benthic organisms in key regions. Light colors show the projected change of present suitable habitat for corals in the Coral Triangle region (A), kelp in South Australia (B) and seagrass in the Mediterranean (C) due to 3-D habitats compression during the 21stcentury (expressed as a \% of present conditions) under the RCP8.5 scenario. The bars in the right express the range of values for scenarios RCP8.5 and RCP4.5. Note the different vertical axis in each panel. 


\section{Reporting Summary}

Nature Research wishes to improve the reproducibility of the work that we publish. This form provides structure for consistency and transparency in reporting. For further information on Nature Research policies, see Authors \& Referees and the Editorial Policy Checklist.

\section{Statistics}

For all statistical analyses, confirm that the following items are present in the figure legend, table legend, main text, or Methods section.

n/a Confirmed

\ $\square$ The exact sample size $(n)$ for each experimental group/condition, given as a discrete number and unit of measurement

Х $\square$ A statement on whether measurements were taken from distinct samples or whether the same sample was measured repeatedly

$\square$ The statistical test(s) used AND whether they are one- or two-sided

$\triangle$ Only common tests should be described solely by name; describe more complex techniques in the Methods section.

Х $\square$ A description of all covariates tested

Х $\square$ A description of any assumptions or corrections, such as tests of normality and adjustment for multiple comparisons

$\square$ A full description of the statistical parameters including central tendency (e.g. means) or other basic estimates (e.g. regression coefficient)

AND variation (e.g. standard deviation) or associated estimates of uncertainty (e.g. confidence intervals)

For null hypothesis testing, the test statistic (e.g. $F, t, r$ ) with confidence intervals, effect sizes, degrees of freedom and $P$ value noted

$\triangle \square$ Give $P$ values as exact values whenever suitable.

Х $\square$ For Bayesian analysis, information on the choice of priors and Markov chain Monte Carlo settings

Х $\square$ For hierarchical and complex designs, identification of the appropriate level for tests and full reporting of outcomes

Х $\square$ Estimates of effect sizes (e.g. Cohen's $d$, Pearson's $r$ ), indicating how they were calculated

Our web collection on statistics for biologists contains articles on many of the points above.

\section{Software and code}

Policy information about availability of computer code

Data collection Data have been collected from public repositories using an ordinary ftp program (FileZilla)

Data analysis The data have been analysed using our own codes written in MATLAB, but the codes are not central to research.

For manuscripts utilizing custom algorithms or software that are central to the research but not yet described in published literature, software must be made available to editors/reviewers. We strongly encourage code deposition in a community repository (e.g. GitHub). See the Nature Research guidelines for submitting code \& software for further information.

\section{Data}

Policy information about availability of data

All manuscripts must include a data availability statement. This statement should provide the following information, where applicable:

- Accession codes, unique identifiers, or web links for publicly available datasets

- A list of figures that have associated raw data

- A description of any restrictions on data availability

All data is available in the main text or the supplementary materials

\section{Field-specific reporting}

Please select the one below that is the best fit for your research. If you are not sure, read the appropriate sections before making your selection.
Life sciences
$\square$ Behavioural \& social sciences
$\bigotimes$ Ecological, evolutionary \& environmental sciences

For a reference copy of the document with all sections, see nature.com/documents/nr-reporting-summary-flat.pdf 


\section{Ecological, evolutionary \& environmental sciences study design}

All studies must disclose on these points even when the disclosure is negative.

Study description The study analyses the projected evolution of 3D temperature fields in the global ocean and how it would affect marine life. It is based on the analysis of global climate simulations and the comparison with published studies of marine life evolution.

Research sample

The study is based on an ensemble of 28 global climate simulations available at https://cmip.Innl.gov/cmip5/data_portal.html.

Sampling strategy

All available models have been considered.

Data collection

Data have been downloaded from https://cmip.IInl.gov/cmip5/data_portal.html

Timing and spatial scale

N/A

Data exclusions

No data have been excluded from the analyses

Reproducibility

N/A

Randomization

N/A

Blinding

$N / A$

Did the study involve field work?

Yes $\quad$ No

\section{Reporting for specific materials, systems and methods}

We require information from authors about some types of materials, experimental systems and methods used in many studies. Here, indicate whether each material, system or method listed is relevant to your study. If you are not sure if a list item applies to your research, read the appropriate section before selecting a response.

Materials \& experimental systems

\begin{tabular}{|c|c|}
\hline $\mathrm{n} / \mathrm{a}$ & Involved in the study \\
\hline Х & $\square$ Antibodies \\
\hline Х & $\square$ Eukaryotic cell lines \\
\hline$凶$ & $\square$ Palaeontology \\
\hline$\unrhd$ & $\square$ Animals and other organisms \\
\hline$\bigotimes$ & $\square$ Human research participants \\
\hline$\bigotimes$ & $\square$ Clinical data \\
\hline
\end{tabular}

Methods

$\mathrm{n} / \mathrm{a}$ Involved in the study

$\bigotimes \square$ ChIP-seq

Х $\square$ Flow cytometry

\) $\square$ MRI-based neuroimaging 